\title{
Pengaruh Dukungan Suami Terhadap Pengurangan Nyeri Persalinan Kala I
}

\author{
Lilik Darwati \\ Prodi Diploma III Kebidanan Universitas Islam Lamongan \\ Email: lilik.dw@gmail.com
}

\begin{abstract}
ABSTRAK
Persalinan adalah proses membuka dan menipisnya serviks dan janin turun ke dalam jalan lahir. Adanya proses tersebut menyebabkan persalinan disertai rasa nyeri. Hasil penelitian menunjukkan ibu yang diberi dukungan selama persalinan mendapatkan rasa aman dan nyaman dari keluargan yang lebih baik. Tujuan penelitian untuk mengetahui pengaruh dukungan suami terhadap pengurangan nyeri persalinan kala I di BPM Lilik Doyomulyo Kembangbahu Lamongan.

Desain penelitian termasuk analitik dengan pendekatan cross sectional. Populasinya semua ibu bersalin kala I. periode Mei 2018. Sampel diambil sebagian ibu bersalin kala I dengan teknik total sampling. Data dikumpulkan dengan menggunakan teknik skala nyeri, observasi dan lembar chek list kemudian dianalisa secara deskriptif dan secara analitik dengan uji Koefisien Kontingensi.

Didapatkan sebagian besar responden mendapat dukungan suami yaitu sebanyak 6 responden $(60 \%)$ dan hampir setengahnya tidak mendapatkan dukungan suami yaitu 4 responden $(40 \%)$. Setengah responden merasakan nyeri ringan yaitu 5 responden $(50 \%)$, hampir setengahnya nyeri sedang yaitu 4 responden (40\%), sebagian kecil nyeri berat yaitu 1 responden $(10 \%)$ dari total 10 responden. Dari hasil analisis didapatkan ada pengaruh dukungan suami terhadap pengurangan nyeri persalinan kala I. (approx.Sig. 0,007 < 0,05) dengan pengaruh kategori positif dan cukup kuat (Contingency Coefficient $+0,707$ ).

Disarankan agar petugas kesehatan selalu memberikan penjelasan kepada semua klien tentang pengaruh dukungan suami terhadap pengurangan nyeri persalinan kala I.
\end{abstract}

\section{Kata Kunci : Dukungan Suami, Nyeri Persalinan Kala I}

\section{PENDAHULUAN}

Persalinan adalah proses membuka dan menipisnya serviks dan janin turun ke dalam jalan lahir. Kelahiran adalah proses dimana janin dan ketuban didorong keluar melalui jalan lahir (Manuaba, 2012). Persalinan dan kelahiran merupakan kejadian fisiologi normal, kelahiran bayi juga merupakan peristiwa sosial yang ibu dan keluarga menantikan selama 9 bulan. Ketika persalinan dimulai, peranan ibu adalah melahirkan bayinya, peranan petugas kesehatan adalah memantau persalinan untuk mendeteksi dini adanya komplikasi, disamping bersama keluarga memberikan motivasi dan dukungan pada ibu bersalin (Penny Simkin dan Ruth Ancheta, 2015).

Nyeri pada persalinan timbul dikarenakan oleh banyak faktor yang mempengaruhi sehingga banyak yang ingin menemukan bagaimana cara menghilangkan nyeri tersebut. Berdasar penelitian menyebutkan bahwa $12 \%$ responden menyatakan bahwa persalinan dengan rasa nyeri merupakan saat-saat menyeramkan. Rasa takut dan stres mengakibatkan pengeluaran adrenalin sehingga menurunkan kontraksi rahim dan menjadikan persalinan semakin lama (http:/www. gkjmb.or.id).

Sekalipun sebagian besar persalinan dapat berjalan lancar, tetapi bukan berarti 
tanpa bahaya karena perubahan keadaan dapat terjadi setiap saat yang membahayakan ibu maupun janin. Dengan demikian setiap persalinan selalu memerlukan pengawasan sehingga pertolongan yang tepat dapat diberikan. Perasaan takut dapat menimbulkan ketegangan sehingga dapat menyebabkan gangguan lahir (Penny Simkin dan Ruth Ancheta, 2015).

Pada saat ini terdapat kebiasaan istri yang meminta suaminya untuk menunggu di dalam kamar bersalin untuk ketenangan serta agar suami dapat merasakan bagaimana penderitaan saat melahirkan. Dalam batas-batas yang wajar permintaan tersebut dapat dibenarkan, bahkan sangat menguntungkan karena suami dapat memberikan dorongan moril dan menambah semangat saat melahirkan (Manuaba, 2012).

Banyak hasil penelitian menunjukkan ibu yang diberi perhatian dan dukungan serta asuhan selama persalinan akan mendapatkan rasa aman dan nyaman dan keluaran yang lebih baik (Enkin Etall, 2000). Hal ini perlu dilakukan karena sebagian besar wanita takut dengan nyeri persalinan. Pada umumnya mereka berfikir akan seperti apakah nyerinya, akan seburuk apa keadaannya, dan apakah dapat menahan rasa nyerinya ? Media informan sering memberikan gambaran persalinan yang sepertinya lama dan menyakitkan bahkan berbahaya. Wanita yang sudah melahirkan kadang-kadang tidak membantu bahkan menyampaikan cerita yang mengerikan tentang persalinan. Akhirnya bayangan akan rasa nyeri dapat membuat wanita menjadi takut dalam persalinan (Nolan, Mary, 2014).

Nyeri persalinan dapat menjadi lebih ringan seiring dengan semakin seringnya ada upaya pengendalian nyeri sehingga ikatan antara persalinan dan nyeri masih kuat. Anggapan yang tetap ada mengenai tak terelakkanya nyeri persalinan, bahkan jika hal itu hadir untuk mempengaruhi ibu agar memikirkan metode pengendalian nyeri yang ia inginkan sebelum melihat persalinan sebagai perjalanan yang berlanjut (Hailldors Dottir \& Karlsdofttif, 2016).

Ada pemahaman faktor fisiologis dapat menyebabkan nyeri persalinan. Hal ini dapat dilihat dengan adanya kontraksi dari pembukaan jalan lahir dari pembukaan nol sampai lengkap (Mander, Nosemary, 2014). Alasan lain yang berperan adalah sebagian besar fasilitas kesehatan memiliki peraturan dan prosedur kurang bersahabat dan menakutkan bagi ibu. Peraturan dan prosedur termasuk tidak memperkenankan anggota keluarga menemani ibu, membatasi ibu hanya posisi tertentu selama persalinan (Asuhan persalinan normal, 2007). Dilihat dari faktor fisiolagis persalinan, fasilitas kesehatan serta dukungan dan perhatian yang kurang maka dengan penelitian ini akan didapatkan informasi yang baik sehingga dapat diberikan solusi cara memberikan asuhan sayang ibu meliputi dukungan tenaga kesehatan, keluarga atau suami, untuk memberikan intruksi tentang posisi, relaksasi agar dapat mengurangi rasa nyeri pada persalinan kala I dan memberikan kebebasan kepada ibu untuk memilih metode pengendalian nyeri yang diinginkan.

Berdasarkan fenomena diatas dan mengingat pentingnya memberikan dukungan selama persalinan Adanya proses tersebut menyebabkan persalinan disertai rasa nyeri. Oleh karenanya banyak yang ingin menemukan cara menghilangkan nyeri tersebut. Saat ini terdapat kebiasaan istri yang meminta suami menunggu di dalam kamar bersalin. Maka dari itu peneliti tertarik untuk mengetahui pengaruh dukungan suami terhadap pengurangan nyeri persalinan kala I di BPM Lilik Doyomulyo Kembangbahu Lamongan. 


\section{METODE PENELITIAN}

Desain penelitian adalah sesuatu yang sangat penting dalam penelitian yang memungkinkan pemaksimalan kontrol beberapa faktor yang bisa mempengaruhi akurasi suatu hasil (Nursalam, 2013: 79). Dalam penelitian ini menggunakan penelitian analitik merupakan survey atau penelitian yang mencoba menggali bagaimana dan mengapa fenomena kesehatan itu terjadi (Notoatmodjo, 2015: 145) maka penelitian ini memiliki variabel independent dan dependent. Pendekatan yang digunakan adalah cross sectional yaitu penelitian yang menekankan pada waktu pengukuran, observasi data variabel independen dan dependen hanya satu kali pada satu saat (Nursalam, 2013: 85).

Lokasi dalam penelitian ini adalah di BPM Lilik Doyomulyo Kembangbahu Lamongan. Waktu penelitian dilaksanakan bulan mei 2018 Variabel bebas adalah dukungan suami dan terikatnya pengurangan nyeri persalinan kala I dikumpulkan dengan lembat cheklis dan skala nyeri. Analisis statistik dilakukan dengan menggunakan teknik statistik menggunakan koefisien kontingensi.

\section{HASIL}

\section{Data Umum}

a. Usia

Karakteristik responden berdasarkan usia di BPM Lilik Doyomulyo Kembangbahu Lamongan. Tahun 2018 dapat dilihat pada diagram 4.1 dibawah ini.

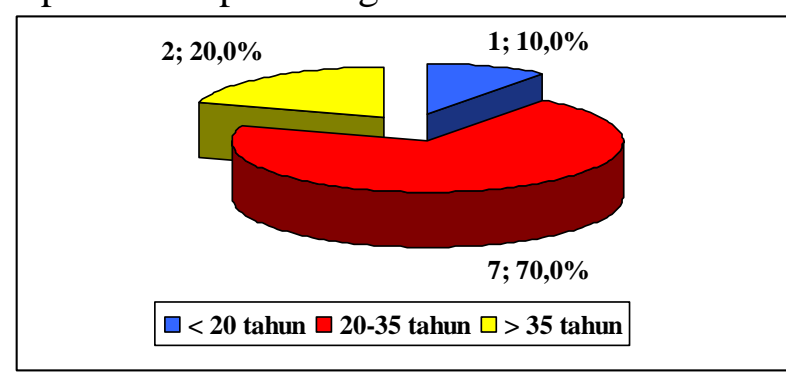

Sumber : Data Primer 2018

Diagram 4.1 Karakteristik Responden Berdasarkan Usia
Berdasarkan Diagram 4.1 diatas diketahui sebagian besar responden berusia 20-35 tahun yaitu sebanyak 7 responden $(70,0 \%)$, dan sebagian kecil yang berusia $<20$ tahun yaitu hanya ada 1 responden $(10,0 \%)$ dan $>35$ tahun 2 responden $(20,0 \%)$ dari total 10 responden.

\section{b. Pendidikan}

Karakteristik responden berdasarkan pendidikan di BPM Lilik Doyomulyo Kembangbahu Lamongan. Tahun 2018 dapat dilihat pada diagram 4.2 dibawah ini.

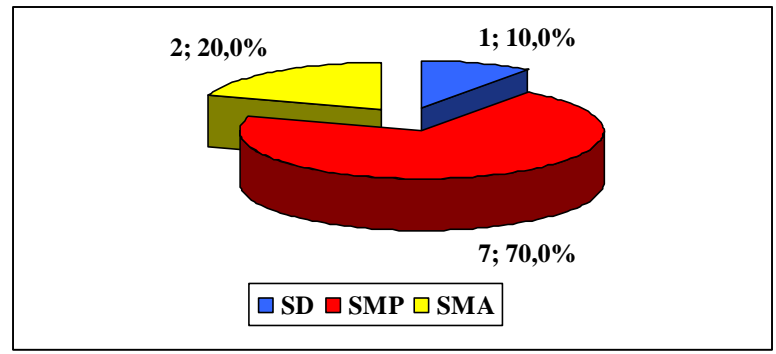

Sumber : Data Primer 2018

Diagram 4.2 Karakteristik Responden Berdasarkan Pendidikan di BPM Lilik Doyomulyo Kembangbahu Lamongan. Tahun 2018

Berdasarkan Diagram 4.2 diatas diketahui sebagian besar responden berpendidikan SMP yaitu sebanyak 7 responden $(70,0 \%)$, dan sebagian kecil yang berpendidikan SD yaitu hanya ada 1 responden $(10,0 \%)$ dan SMA 2 responden $(20,0 \%)$ dari total 10 responden.

\section{c. Pekerjaan}

Karakteristik responden berdasarkan pekerjaan di BPM Lilik Doyomulyo Kembangbahu Lamongan. Tahun 2018 dapat dilihat pada diagram 4.3 dibawah ini.

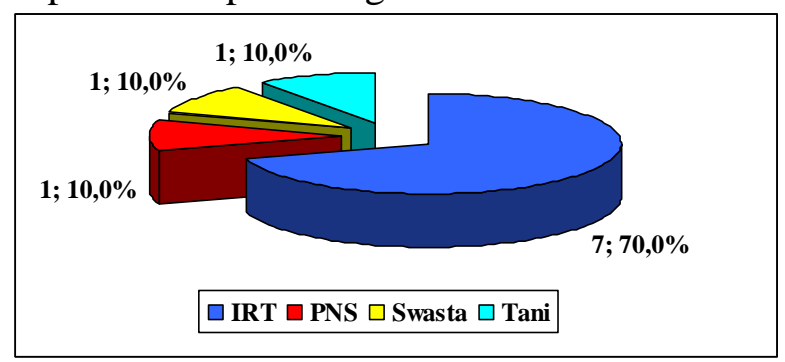

Sumber : Data Primer 2018 


\section{Diagram 4.3 Karakteristik Responden Berdasarkan Pekerjaan}

Berdasarkan Diagram 4.3 diatas diketahui sebagian besar responden bekerja sebagai IRT yaitu sebanyak 7 responden $(70,0 \%)$, dan sebagian kecil yang bekerja sebagai PNS, Swasta maupun Tani yaitu masing-masing hanya ada 1 responden $(10,0 \%)$ dari total 10 responden.

\section{Data Khusus}

a. Dukungan Suami dalam Persalinan Kala I

Dukungan suami dalam persalinan kalaI di BPM Lilik Doyomulyo Kembangbahu Lamongan. Tahun 2018 dapat dilihat pada diagram 4.4 dibawah ini.

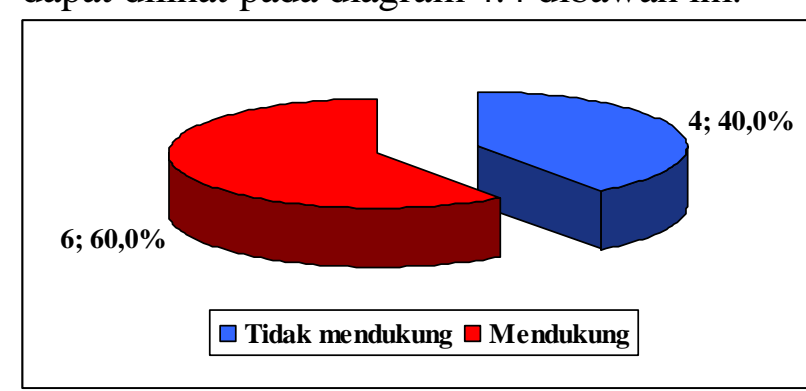

Sumber : Data Primer 2018

Diagram 4.4 Dukungan Suami dalam Persalinan Kala I

Berdasarkan Diagram 4.4 diatas diketahui sebagian besar responden mendapatkan dukungan dari suami dalam menghadapi persalinan kala I yaitu sebanyak 6 responden $(60,0 \%)$ dan hampir setengah responden tidak mendapatkan dukungan dari suami yaitu sebanyak 4 responden $(40,0 \%)$ dari total 10 responden.

\section{b. Pengurangan Nyeri Persalinan Kala I}

Pengurangan nyeri persalinan kala I di BPM Lilik Doyomulyo Kembangbahu Lamongan. Tahun 2018 dapat dilihat pada diagram 4.2 dibawah ini.

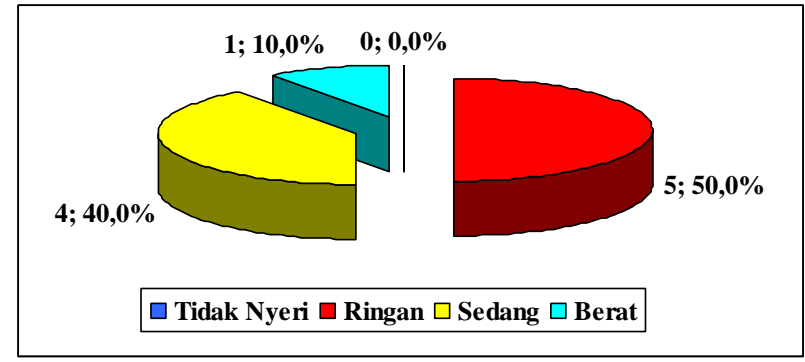

Sumber : Data Primer 2018

Diagram 4.5 Pengurangan

Nyeri

Persalinan Kala I

Berdasarkan Diagram 4.5 diatas diketahui setengah responden merasakan nyeri persalinan dengan kategori ringan yaitu ada 5 responden $(50,0 \%)$, hampir setengahnya merasakan nyeri sedang yaitu ada 4 responden $(40,0 \%)$, sebagian kecil nyeri berat yaitu 1 responden $(10,0 \%)$ dan tidak satupun yang tidak merasakan nyeri persalinan dari total 10 responden.

c. Pengaruh Dukungan Suami terhadap Pengurangan Nyeri Persalinan Kala I

Pengaruh dukungan suami terhadap pengurangan nyeri persalinan kala I di BPM Lilik Doyomulyo Kembangbahu Lamongan. Tahun 2018 dapat dilihat pada tabel silang dibawah ini.

Tabel 4.3 Pengaruh Dukungan Suami terhadap Pengurangan Nyeri Persalinan Kala I

\begin{tabular}{|c|c|c|c|c|c|c|}
\hline \multirow{2}{*}{\multicolumn{3}{|c|}{ Dukungan $*$ Nyeri }} & \multicolumn{3}{|c|}{ Nyeri } & \multirow{3}{*}{$\begin{array}{r}\text { Total } \\
4\end{array}$} \\
\hline & & & \multirow{2}{*}{$\begin{array}{r}\text { Ringan } \\
0\end{array}$} & \multirow{2}{*}{\begin{tabular}{|}
$\begin{array}{c}\text { Seda } \\
\text { ng }\end{array}$ \\
3
\end{tabular}} & \multirow{2}{*}{$\frac{\text { Berat }}{1}$} & \\
\hline \multirow{4}{*}{$\begin{array}{l}\text { Du- } \\
\text { kung } \\
\text { an }\end{array}$} & \multirow{2}{*}{$\begin{array}{l}\text { Tidak } \\
\text { ada du- } \\
\text { kungan }\end{array}$} & Jumlah & & & & \\
\hline & & $\begin{array}{l}\% \text { dari } \\
\text { total }\end{array}$ & $0 \%$ & $\begin{array}{r}30,0 \\
\%\end{array}$ & $\begin{array}{r}10,0 \\
\%\end{array}$ & $40,0 \%$ \\
\hline & \multirow{2}{*}{$\begin{array}{l}\text { Ada } \\
\text { Du- } \\
\text { kungan }\end{array}$} & Jumlah & 5 & 1 & 0 & 6 \\
\hline & & $\begin{array}{l}\% \text { dari } \\
\text { total }\end{array}$ & $50,0 \%$ & $\begin{array}{r}10,0 \\
\%\end{array}$ &, $0 \%$ & $60,0 \%$ \\
\hline \multirow{2}{*}{\multicolumn{2}{|c|}{ Total }} & Jumlah & 5 & 4 & 1 & 10 \\
\hline & & $\begin{array}{l}\% \text { dari } \\
\text { total }\end{array}$ & $50,0 \%$ & $\begin{array}{r}40,0 \\
\%\end{array}$ & $\begin{array}{r}10,0 \\
\%\end{array}$ & $100,0 \%$ \\
\hline
\end{tabular}

Sumber : Data Primer 2018

Berdasarkan Tabel 4.3 diatas diketahui pada kategori tidak ada dukungan maka frekuensi kriteria nyeri persalinan paling banyak adalah kriteria sedang, adapun pada kategori ada dukungan kriteria nyeri persalinan paling banyak adalah kriteria kriteria ringan. 
Dapat dilihat ada kecenderungan semakin ada dukungan maka semakin ringan kriteria nyeri persalinan yang dirasakan ibu bersalin.

Guna membuktikan apakah kecenderungan tersebut memiliki pengaruh yang bermakna secara statistik atau tidak, maka dilakukan uji hubungan dengan menggunakan teknik uji Koefisien Kontingensi. Pengujian Koefisien Kontingensi dengan menggunakan SPSS 12 didapatkan hasil sebagai berikut :

Tabel 4.4 Hasil Uji Pengaruh Dukungan Suami terhadap Pengurangan Nyeri Persalinan Kala I

\begin{tabular}{|l|l|c|l|}
\hline \multicolumn{2}{|l|}{} & Value & $\begin{array}{l}\text { Approx } \\
\text {.Sig. }\end{array}$ \\
\hline $\begin{array}{l}\text { Nominal by } \\
\text { Nominal }\end{array}$ & $\begin{array}{l}\text { Contingency } \\
\text { Coefficient }\end{array}$ &, 707 &, 007 \\
\hline \multicolumn{2}{|l|}{ N of Valid Cases } & 10 & \\
\hline
\end{tabular}

Berdasarkan Tabel 4.4 diatas didapatkan nilai approx.Sig. sebesar 0,007 $<0,05$, maka Ho ditolak. Hal ini berarti ada pengaruh dukungan suami terhadap pengurangan nyeri persalinan kala I di BPM Lilik Doyomulyo Kembangbahu Lamongan. Tahun 2018 dengan pengaruh yang positif dan cukup kuat (Contingency Coefficient + 0,707).

\section{PEMBAHASAN}

Dukungan Suami dalam Menghadapi Persalinan Kala I

Berdasarkan Diagram 4.1 diketahui sebagian besar responden mendapatkan dukungan dari suami dalam menghadapi persalinan kala I yaitu sebanyak 6 responden $(60 \%)$ dari total 10 responden, dengan paling banyak berupa dukungan gosok punggung.

Kemampuan mengontrol diri menurun terjadi pada ibu bersalin kala I masa aktif. Untuk itu dapat diberikan support emosi dan fisik, melibatkan orang terdekat (suami) untuk selalu mendampingi selama proses persalinan berlangsung. Berdasarkan hasil penelitian, pemberian dukungan fisik, emosional dan psikologis selama persalinan akan dapat membantu mempercepat proses persalinan dan membantu ibu memperoleh kepuasan dalam melalui proses persalinan normal. Dukungan suami merupakan setiap kekuatan atau dorongan yang ada pada diri seorang suami yang dapat memberi motivasi dan mendampingi istri dalam menghadapi sesuatu masalah atau perjuangan. Dukungan dari suami sangat diperlukan karena setiap wanita apabila menghadapi persalinan pasti dihinggapi perasaan tidak kuat, tidak berani menanggung segala cobaan dan rasa-rasa lemah hati, takut, ngeri serta gelisah dan tidak tenang. Semua menjadi intensif pada saat mendekati masa kelahiran (Dr. Kartini, Kartono: 2013).

Berdasarkan hasil penelitian didapatkan sebagian besar responden mendapatkan dukungan dari suami dalam menghadapi persalinan kala I. Kondisi ini menggambarkan bahwa sebagian besar ibu bersalin telah mendapatkan motivasi dari suami sehingga secara pasikologis mendapatkan tambahan kekuatan untuk menghadapi proses persalinan yang akhirnya persalinan dapat berjalan lebih lancar. Melalui motivasi ini timbul semangat dan kekuatan dari ibu bersalin untuk melanjutkan proses persalinan dan siap menghadapi rasa nyeri yang terjadi selama proses persalinan. Dukungan dari suami sangat diperlukan karena berdasarkan hasil penelitian diketahui bahwa pemberian dukungan secara fisik, emosional dan psikologis selama persalinan akan dapat membantu mempercepat proses persalinan dan membantu ibu memperoleh kepuasan dalam melalui proses persalinan normal.

Pengurangan Nyeri Persalinan Kala I 
Berdasarkan diagram 4.2 diketahui setengah responden merasakan nyeri dengan kategori ringan yaitu ada 4 responden (40\%) dari total 10 responden.

Berkaitan dengan hal ini perlu disampaikan disini yang dimaksud dengan nyeri adalah perasaan tidak nyaman yang betul-betul subyektif yang hanya orang yang menderitanya yang dapat menjelaskan dan mengevaluasi (Long, 2016). Atas dasar rasa nyeri yang dirasakan maka nyeri dapat dibedakan menjadi beberapa tingkat nyeri. Menurut Pottery \& Perry (2015) rasa nyeri dibedakan ke dalam 4 skala atau tingkat yaitu tidak nyeri (dalam pengukuran ditentukan oleh warna hijau), nyeri ringan (dinyatakan dengan warna kuning), nyeri sedang (dinyatakan dengan warna orange) dan nyeri berat (dinyatakan dengan warna merah). Pada persalinan hampir selalu disertai dengan rasa nyeri bagi ibu bersalin. Nyeri persalinan pada beberapa wanita ada yang jarang mengalaminya, tetapi lebih sering dijumpai wanita yang beranggapan bahwa nyeri persalinan merupakan sesuatu hal yang luar biasa (Nolan, Mary : 2013). Menurut Tjokronegoro (2016) nyeri persalinan kala I timbul karena adanya kontraksi rahim yang menyebabkan regangan mulut rahim yang akhirnya regangan ini menimbulkan rasa nyeri. Selain itu juga disebabkan adanya peregangan rahim bagian bawah, iskemia rahim bagian bawah dan tarikan ligamentum.

Atas dasar hasil penelitian didapatkan setengah responden merasakan nyeri dengan kategori ringan. Hal ini memberikan gambaran setengah responden persalinannya dirasakan dengan disertai rasa nyeri ringan. Penyebab timbulnya rasa nyeri ringan tersebut dipengaruhi oleh anggapan dan cara mengartikan nyeri yang berbeda pada setiap orang. Banyak faktor yang mempengaruhi cara mengartikan nyeri dari setiap individu antara lain faktor usia, jenis kelamin, latar belakang, sosiokulture, lingkungan, pengalaman sekarang dan pengalaman yang lalu.

Usia merupakaan salah satu faktor yang dapat mempengaruhi rasa nyeri persalinan. Atas dasar hasil penelitian didapatkan sebagian besar responden berusia 20-35 tahun. Usia ini merupakan usia reproduktif bagi ibu dan termasuk golongan dewasa muda. Dengan demikian merupakan usia siap untuk hamil dan bersalin dengan resiko minimal. Adanya proses persalinan dengan resiko minimal ini membawa dampak pada lancarnya proses persalinan sehingga memperkecil nyeri persalinan.

Latar belakang merupakan salah satu faktor yang ikut mempengaruhi nyeri persalinan. Latar belakang responden bisa beragam, misalnya latar belakang pendidikan maupun pekerjaan. Atas dasar pendidikan sebbagian besar responden berpendidikan SMP. Dengan pendidikannya ini responden memiliki kemampuan berfikir lebih baik dibandingkan dengan mereka yang berpendidikan SD atau tidak tamat SD. Hal ini membawa pengaruh kepada mudahnya menerima penjelasan dari penolong persalinan mengenai proses persalinan dar rasa nyeri yang menyertainya. Dengan demikian secara psikologis rasa nyeri yang timbul akan direspon secara wajar dan dianggap sesuatu yang biasa terjadi. Atas dasar latar belakang pekerjaan, sebagian besar responden sebagai ibu rumah tangga (IRT). Kondisi ini membawa dampak pada kebiasaan ibu bekerja sehari-hari dirumah. Kesulitan dalam menghadapi pekerjaan sehari-hari membawa ibu lebih mandiri dalam menghadapi setiap masalah seperti tidak terlalu mempermasalahkan adanya rasa nyeri persalinan yang sedang dihadapinya.

Lingkungan menyangkut berbagai hal yang ada disekitar individu, baik fisik maupun psikologis. Secara fisik, suami 
termasuk dalam kategori lingkungan fisik berupa wujud zat sebagai manusia atau suami. Dukungan suami merupakan lingkungan psikologis untuk mengendalikan nyeri. Dampak dari kondisi ini adalah rasa nyeri yang timbul dapat diterima sebagai suatu bagian dari bukti kasih sayang sehingga secara subyektif diterima dengan senang hati yang akhirnya nyeri yang dirasakan diartikan sebagai sesuatu yang biasa.

Pengaruh Dukungan Suami terhadap Pengurangan Nyeri Persalinan Kala I

Ada pengaruh dukungan suami terhadap pengurangan nyeri persalinan kala I di di BPM Lilik Doyomulyo Kembangbahu Lamongan. Tahun 2018 (approx.Sig. sebesar 0,007 < 0,05), maka Ho ditolak) dengan pengaruh yang positif dan cukup kuat (Contingency Coefficient + 0,707) (Sulaiman, $2013:$ 137).

Pemberian dukungan fisik, emosional dan psikologis selama persalinan akan dapat membantu mempercepat proses persalinan dan membantu ibu memperoleh kepuasan dalam melalui proses persalinan normal. Sementara itu setiap proses persalinan akan mengalami kontraksi. Kontraksi merupakan suatu kekuatan pada ibu yang dapat menyebabkan serviks membuka dan mendorong kepala turun dan mulai masuk ke dalam rongga panggul serta menyebabkan rasa nyeri pada perut sampai menjalar pada pinggang (Manuaba: 2012).

Jika didapatkan ada pengaruh dukungan suami terhadap pengurangan nyeri persalinan kala I membuktikan bahwa dukungan suami dapat menjadi motivasi bagi ibu bersalin yang secara psikologis disikapi dengan perasaan senang dalam menghadapi persalinan. Kondisi senang inilah yang membuat ibu merasa semangat menjalani proses persalinan sehingga rasa nyeri yang menyertai persalinan dirasakan sebagai suatu bentuk perjuangan dan bisa dikendalikan oleh ibu. Sesuai hasil penelitian didapatkan sebagian besar responden mendapatkan dukungan dari suami dalam menghadapi persalinan kala I dan ternyata setengah responden merasakan nyeri dengan kategori ringan.

\section{KESIMPULAN DAN SARAN}

Sebagian besar responden mendapatkan dukungan dari suami dalam menghadapi persalinan kala I yaitu sebanyak 6 responden $(60 \%)$ dari total 10 responden.

Setengah responden merasakan nyeri dengan kategori ringan yaitu ada 4 responden (40\%) dari total 10 responden.

Ada pengaruh dukungan suami terhadap pengurangan nyeri persalinan kala I Adanya proses tersebut menyebabkan persalinan disertai rasa nyeri. Oleh karenanya banyak yang ingin menemukan cara menghilangkan nyeri tersebut. Saat ini terdapat kebiasaan istri yang meminta suami menunggu di dalam kamar bersalin. Hasil penelitian menunjukkan ibu yang diberi dukungan selama persalinan mendapatkan rasa aman dan nyaman dari keluaran yang lebih baik. Tujuan penelitian ini adalah untuk mengetahui pengaruh dukungan suami terhadap pengurangan nyeri persalinan kala I di BPM Lilik Doyomulyo Kembangbahu Lamongan. Tahun 2018 (approx.Sig. sebesar 0,007 < 0,05), maka Ho ditolak) dengan pengaruh yang positif dan cukup kuat (Contingency Coefficient + 0,707).

\section{DAFTAR PUSTAKA}

Azwar, Saifudin. Sikap Manusia Teori Dan Pengukurannya. Jogyakarta Pustaka Pelajar. 
Dr. Kartini, Kartono (2013). Psikology

Wanita. PT rajawali, jakarta.

Jaringan Nasional Pelatihan Klinik Kesehatan Reproduksi. (2012). Buku Acuan Asuhan Persalinan Normal. Jakarta : JHPIEGO Dan Departemen Kesehatan Republik Indonesia.

Long, Barbara. (2016). Perawatan Medical Bedah, Bandung : Yayasan Ikatan Alumni Pendidikan Keperawatan Padjajaran. Bandung.

Mander Rose Mary. (2004). Nyeri persalinan. Jakarta EGC.

Manuba, I Gde Bagus.(2012). Ilmu Kebidanan Penyakit Kandungan Dan Keluarga Berencaa Untuk Pendidikan Bidan. Jakarta : EGC.

Mochtar rustam. (2012). Sinopsis Abstetri Fisiologi Edisi 2. Jakarta : EGC.

Nolan, Mary.(2014). Kehamilan Dan Melahirkan. Jakarta : Arcan

Notoadmodjo, Soekidjo. (2015). Metodologi Penelitian Kesehatan. Jakarta. PT. Rhineka Cipta.

Nursalam (2013). Konsep Dasar Penerapan Metodologi Penelitian Kesehatan. Jakarta : Rhineka Cipta.

Penny Simkin Dan Ruth Ancheta. (2015).

The labor progress handbook. Jakarta : EGC.

Pottery dan Perry. (2015). Fundamental Keperawatan. Jakarta : EGC

Sarwono Prawirohardjo. (2012). Ilmu Kebidanan. Yayasan Bina Pustaka.
Tjokro Nosoro Arjatmo. (2016). Penanggulangan Nyeri Pada Persalinan. Jakarta FKUI.

Wiknjosastro, Hanifa. (2012). Ilmu Kebidanan. Jakarta Yayasan Bina Pustaka Sarwono Prawirohardjo.

Yuwono, T. (2016). Kamus Lengkap Bahasa Indonesia Praktis. Surabaya Arloka.

http:www.Gkjmb.or id/buletin 12/infosehat/htm.

http:www.Islight.com 